\title{
Primary cilia distribution and orientation during involution of the bovine mammary gland
}

\author{
J. Biet, ${ }^{*}{ }^{1}$ C. A. Poole,$\ddagger^{2}$ K. Stelwagen, $\S$ J. K. Margerison,\# and K. Singh ${ }^{\star 3,4}$ \\ *AgResearch Ltd., Ruakura Research Centre, Private Bag 3123, Hamilton 3240, New Zealand \\ †Institute of Agriculture and Environment, College of Sciences, Massey University, PB 11222, Palmerston North 4442, New Zealand \\ łDepartment of Medicine, Dunedin School of Medicine, University of Otago, PO Box 913, Dunedin 9054, New Zealand \\ §SciLactis Ltd., Waikato Innovation Park, Ruakura Road, Hamilton 3240, New Zealand \\ \#Bioscience and Animal Science, University of Nottingham, Sutton Bonington, Leicestershire, LE12 5RD, United Kingdom
}

\begin{abstract}
The regulation of mammary gland involution occurs through multiple levels including environmental factors, hormones, and local intramammary signals. Primary cilia (PC) are signaling organelles that sense biochemical and biophysical extracellular stimuli and are vital for cellular and tissue function. The aim of this study was to examine the distribution, incidence, and orientation of PC. Furthermore, we determined changes in expression levels of the signal transducer and activator of transcription (STAT) 6 at the onset of bovine mammary gland involution. Mammary tissue was collected from pasture-fed, primiparous, nonpregnant Friesian dairy cows at mid lactation $(\mathrm{n}=5$ per group) killed 6 - $\mathrm{h}$ after milking (lactating controls) and during involution after 7 and $28 \mathrm{~d}$ of nonmilking (NM). Fluorescent immunohistochemistry and confocal microscopy of tissue sections showed that $\mathrm{PC}$ were present on luminal secretory epithelial cells (SEC), myoepithelial cells (MEC), and stromal fibroblast cells (SFC). Furthermore, in all 3 experimental groups, different PC positions or orientations relative to the cell surface were identified on SEC and MEC, which projected toward the lumen and were either straight, bent, or deflected against the apical cell surface, whereas PC in SFC were confined to the interalveolar space. However, by 28-d NM, fewer $\mathrm{PC}$ projected into the luminal space and most appeared deflected or projected toward the interalveolar space. Furthermore, by 28-d NM, with the increase in stromal connective tissue, more $\mathrm{PC}$ were detected within the interalveolar and interlobular stroma. At 28-d NM, we observed a decrease in luminal cilia relative to the total number of cilia. The number of ciliated cells in the total
\end{abstract}

Received October 3, 2015.

Accepted December 20, 2015.

${ }^{1}$ Present address: Auckland 0624, New Zealand.

${ }^{2}$ Present address: Wanaka, Central Otago 9305, New Zealand.

${ }^{3}$ Present address: Hamilton 3200, New Zealand.

${ }^{4}$ Corresponding author: kuljeet.singhparhar@outlook.com fraction (SEC, MEC, and SFC) was the same for all 3 groups, although in the luminal fraction (SEC and MEC), PC per nuclei increased by 28-d NM relative to lactation. At all 3 stages, we detected variations in shape and orientation of PC within the same alveolus, with some PC projecting directly into lumen, whereas others appeared to be bent or deflected flat against the cell surface. Within each treatment, the average number of bent cilia was low, whereas the average number of deflected cilia was higher than the average number of cilia projecting directly into the lumen. Quantitative real-time reverse transcription PCR analysis showed that expression levels of milk protein genes $\left(\alpha_{\mathrm{S1}_{1}}\right.$-casein, $\alpha$-lactalbumin, and $\kappa$-casein) declined and that of lactoferrin increased in the involuted mammary tissue following NM, compared with lactating controls. Although STAT6 mRNA levels did not change following NM, STAT6 protein levels did increase following 28-d NM compared with the control lactation group. In conclusion, PC were detected in all cell types in the mammary gland, and changes in orientation during involution suggest the potential for PC to play a role in signal transduction through both mechanosensation and chemosensation. Furthermore, the STAT6-mediated signaling pathway may have a role during involution of the mammary gland.

Key words: primary cilia, bovine mammary gland, mechanotransduction, involution, signal transducer and activator of transcription 6 (STAT6)

\section{INTRODUCTION}

Milk production in dairy cattle declines following peak lactation primarily due to increased loss of secretory epithelial cells (SEC) via apoptosis (Wilde et al., 1997). Mammary function is regulated not only at the hormonal level (Wilde et al., 1999) - local intramammary signals also play a role in initiating SEC apoptosis and involution (Quarrie et al., 1994; Wilde et al., 1997). The primary signal that initiates the involution process is unknown. However, several mechanisms have 
been postulated, including the accumulation in milk of regulatory factors such as a putative feedback inhibitory factor (Wilde et al., 1999), milk casein fractions (Shamay et al., 2003), and serotonin (Collier et al., 2012). Alternatively, physical distension of the mammary gland, which results in changes in cell shape, may activate mechanotransduction pathways, resulting in loss of tight junction integrity and cell-extracellular survival signaling (Davis et al., 1999; Stelwagen, 2001). In support, cell-cell communications via tight junction proteins (Cooper et al., 2004) and cell-extracellular matrix communication (Singh et al., 2005) are disrupted following milk engorgement at the onset of involution of the bovine mammary gland. Furthermore, mammary cell stretch in vitro was associated with the induction of apoptotic pathways (Quaglino et al., 2009) and acute physical distension of rat mammary glands in vivo accelerated the onset of apoptosis of SEC, activation of the pro-apoptotic marker signal transducer and activator of transcription (STAT) 3 , and the loss of extracellular matrix $\beta 1$-integrin adhesion receptors and the tight junction factor occludin (Phyn et al., 2007).

Cells sense and transform the various forms of external stimuli they receive through interactions with the extracellular matrix, neighboring cells, and soluble cues from the microenvironment into a cascade of cellular and molecular events (DuFort et al., 2011). Important differences exist between force-generated or mechanical signaling [e.g., bending of the primary cilium (PC)] and chemical signaling (e.g., soluble signals, such as growth factors; Wells, 2013). Mechanical signals can be highly directional and thereby convey and transmit complex information in 3 dimensions. Soluble factors, on the other hand, diffuse radially, provide limited directional information, and require translation into secondary messengers. Consequently, unlike soluble signals, force-mediated signals can begin and end rapidly (Wells, 2013) and are at least 40 times faster than growth factor-induced signal transduction ( $\mathrm{Na}$ et al., 2008).

The transduction of physical forces appears to occur through changes in protein conformation (Schwartz, 2010). These force-induced effects on conformational change represent a general mechanism that may regulate enzymatic activity, enable new molecular interactions, open mechanosensitive protein channels, or liberate soluble bound factors, which in turn may activate signaling pathways in an autocrine or paracrine fashion (Hoey et al., 2012; Jones and Nauli, 2012). Therefore, mechanical and chemical signals are often interdependent (Wells, 2013). Hence, mechanical forces can act directly and indirectly on chemical signals but seem to exceed the speed of signaling through soluble factors by several orders of magnitude (DuFort et al., 2011; Wells,
2013). Nonetheless, the mechanical forces experienced by cells are generally small. Therefore, the force sensor must either be much more sensitive than the typical protein complex, or highly elongated and projected into the environment to sense and amplify the force experienced (Janmey and McCulloch, 2007).

The PC differ significantly from motile cilia (Barnes, 1961); their singularity, universality, and structural characteristics indicate a role in sensing and transducing several biochemical and biophysical extracellular stimuli in different tissues and organs. Protrusion of a PC into the extracellular space enables access to the cell's external milieu, its elongated geometry provides a high surface-to-volume ratio, and the regulated entry of proteins into the cilium leads to specialization and compartmentalization (Singla and Reiter, 2006; Hoey et al., 2012). Sensory modalities such as mechanical stimulation (bending of the cilium), chemosensation (detection of a specific ligand, growth factor, hormone, or morphogen), or in some cases stimulation by light, temperature, osmolality, or gravity are achieved by a bilayered lipid membrane that is continuous with the plasma membrane of the cell body but contains a distinct subset of receptors and other proteins involved in signaling (Veland et al., 2009; Jones and Nauli, 2012)

The occurrence of the PC is a cell cycle-dependent and dynamic process of assembly and resorption (Nguyen and Jacobs, 2013). During interphase, assembly of the PC will occur on nonproliferating $\mathrm{G}_{0}-\mathrm{G}_{1}$ cells. Primary cilia arise from a basal body, derived from the mother centriole, anchoring the cilium to the cell's microtubular cytoskeleton, whereas intraflagellar transport mechanisms controls its length (Satir and Christensen, 2007). Furthermore, a close structural interrelationship between PC, the secretory organelles, and the extracellular matrix has been identified that indicates a potential role for PC to act as a multifunctional, cellular probe mediating the interaction between connective tissue cells and their biomechanically functional extracellular matrix (Poole et al., 1985). The analysis of PC of various established kidney cell lines demonstrated that PC bend in response to fluid flow (Roth et al., 1988) and thus, $\mathrm{PC}$ have a mechanosensory role via detection of fluid flow across kidney cells (Schwartz et al., 1997). Further experimental evidence indicates that mechanically stimulated cilia are part of a calcium signaling system (Praetorius and Spring, 2001). Additionally, a study with chondrocytes provided evidence that PC are required for ATP-induced $\mathrm{Ca}^{2+}$ signaling (Wann et al., 2012). In the bovine mammary gland, the presence of PC on SEC and MEC was first demonstrated by Nickerson (1989). More recently, PC incidence and celltype distribution and morphology have been described during lactation, milk stasis, and early involution, 
suggesting a potential mechanosensory role the bovine mammary gland (Millier et al., 2013).

Mechanical forces imposed upon a cellular network initiate changes in levels of intracellular calcium. The PC contributes to this response by amplifying mechanical cues through a 2-step process: an immediate response of ciliary bending and subsequent activation of the polycystin complex, leading to an increase in intracellular calcium; and a long-term response mediated through cellular adaption and cytoskeletal rearrangements (Poelmann et al., 2008; Abou Alaiwi et al., 2009; Jones and Nauli, 2012).

The polycystins are a family of integral membrane proteins divided into polycystin-1 (PC-1) and polycystin-2 (PC-2) topologies, with physical interaction between PC-1 and PC-2 accomplished through their C-terminal cytoplasmic domains (Zhou, 2009). Together they comprise a mechanosensitive heterodimeric calcium channel from the family of transient receptor potential ion channels regulating calcium entry and activity. Polycystin-1 is thought to function as a Gprotein-coupled receptor and its domain structure suggests that it acts as a cell surface receptor in both cell-cell and cell-matrix interactions. Polycystin-2, on the other hand, is presumed to form a cation-selective ion channel permeable to $\mathrm{Ca}^{2+}$.

A novel signaling mechanism has been revealed by which PC-1 regulates STAT6-dependent transcription in kidney cells (Low et al., 2006; Olsan et al., 2011). In addition to mediating the mechanosensitive calcium influx, PC-1 also undergoes posttranslational processing in the absence of fluid flow, resulting in cleavage of the carboxy-terminal region (Berbari et al., 2009). The carboxy-terminal region translocates to the nucleus, where it associates with STAT6 and the co-activator p100 to activate STAT6-dependent transcription (Low et al., 2006; Berbari et al., 2009; Olsan et al., 2011). The STAT6 transcription factor is widely expressed in many tissues, including the mammary gland, where it has been shown to be important for alveolar differentiation and proliferation (Clarkson et al., 2004; Low et al., 2006; Khaled et al., 2007). Furthermore, its coactivator p100 is strongly upregulated in SEC during lactation (Broadhurst and Wheeler, 2001). Whereas mechanosensitive calcium signaling results in a fast and temporary cellular response, the STAT6-mediated signaling pathway is proposed to play a role in long-term responses to changes in fluid flow in kidney cells (Low et al., 2006).

The aim of this study was to investigate the presence of PC and the regulation of the STAT6 transcription factor following extended periods of nonmilking in dairy cattle. An immunofluorescent dual-staining method was applied to specifically detect PC distribution, in- cidence, appearance, and orientation in the mammary gland. To gain an understanding of the potential role of the STAT6 transcription factor, gene and protein levels were determined to detect changes following extended periods of nonmilking.

\section{MATERIALS AND METHODS}

\section{Animals and Tissue Collection}

All animal experimental procedures were conducted in compliance with the Ruakura Animal Ethics Committee (Hamilton, New Zealand). Mammary alveolar tissue samples were used from a subset obtained from an animal experiment described previously (Mallah et al., 2013). Briefly, Friesian primiparous, nonpregnant dairy heifers $(97 \pm 2$ DIM) were pasture-fed, milked twice daily, and free of any intramammary infection. For this study, mammary alveolar tissue was obtained at slaughter from lactating cows 6-h postmilking (control), and cows with nonmilking intervals of either 7 (7-d NM) or 28 d (28-d NM) (n = 5 per group). Approximately $30 \mathrm{~g}$ was dissected from the middle of the upper one-third of the gland of a rear quarter of each animal, snap-frozen in liquid nitrogen, and stored at $-80^{\circ} \mathrm{C}$ for subsequent RNA and protein extraction. Additionally, mammary alveolar tissue of $1.5 \mathrm{~cm}$ thickness was fixed in $4 \%$ phosphate-buffered paraformaldehyde, and processed into wax as described previously (Singh et al., 2005). Serial sections $(7 \mu \mathrm{m}$ thick) of approximately $15 \times 20 \mathrm{~mm}^{2}$ cross-sectional area were cut onto polylysine-coated glass slides (BioLab Scientific, Auckland, New Zealand) for histological analysis using $40 \times$ and $100 \times$ objectives.

\section{Fluorescent Immunohistochemistry}

One slide from each serial section ( $\mathrm{n}=5$ per group) from the lactating (control), 7-d NM, and 28-d NM groups was examined histologically by staining with hematoxylin and eosin. For subsequent immunofluorescent staining of PC, tissue sections from 3 cows per group were selected based on the $\alpha_{\mathrm{S1}}$-casein mRNA levels in each animal. Animals with high levels of $\alpha_{\mathrm{S} 1}$-casein mRNA were chosen for the control group, whereas animals with low levels of $\alpha_{\mathrm{S1}^{-}}$-casein mRNA were selected for the 7-d NM and 28-d NM groups. The procedure for dual labeling of PC was carried out as described previously with minor modifications. Centrioles were detected by applying anti- $\gamma$-tubulin antibody; clone GTU-88 (Sigma, St. Louis, MO), at 1:3,000 overnight at $4^{\circ} \mathrm{C}$. The axoneme was detected by applying the anti-acetylated- $\alpha$-tubulin, clone C3B9 (Woods et al., 1989), antibody at 1:300 for $1 \mathrm{~h}$ at $37^{\circ} \mathrm{C}$. Second- 
ary antibodies AlexaFluor 488 and 546 goat anti-mouse IgG (Molecular Probes/Life Technologies, Carlsbad, CA) were applied at 1:500 for $1 \mathrm{~h}$ at room temperature. Nuclei were stained using Hoechst $33258(0.66 \mu \mathrm{g} /$ $\mathrm{mL}$ in PBS; Molecular Probes/Life Technologies) and coverslips were mounted using Prolong Gold mounting medium (Molecular Probes/Life Technologies).

\section{Confocal Microscopy}

Each tissue section per glass slide was divided into 10 equal-sized areas. Per area, at least one alveolus was imaged using a Zeiss LSM 510 Meta laser scanning confocal microscope with a $100 \times$, numerical aperture $=1.40$, oil immersion objective (Zeiss, Oberkochen, Germany) at the Biomedical Imaging Research Unit (BIRU) at the University of Auckland. A series of Zstacks was used to image PC at immunofluorescentspecific laser excitation lines 488 and $543 \mathrm{~nm}$. Nuclei were imaged in the mid-section of the Z-stack using standard fluorescence excitation. ImageJ $1.45 \mathrm{~s}$ software (National Institutes of Health, Bethesda, MD) was used to process all laser scanning microscope files, create composite RGB micrographs, enhance contrast, and add scale bars.

\section{Primary Cilia Analysis}

Using suitable double immunofluorescent-labeled composite micrographs of mammary tissue sections, PC distribution, incidence, and orientation were assessed. To eliminate potential errors due to increased background fluorescence, only clearly interpretable images, where the PC orientation and cells of origin could be identified, were used. Defined by the angle of orientation relative to an orientation directly perpendicular to the alveolar wall (i.e., straight), a cilium was classed as "deflected" if its axoneme lay at an angle greater than $45^{\circ}$ in either direction from the perpendicular angle. If the base of the axoneme appeared to be perpendicular but its tip was almost parallel to the cell surface, the PC was classed as "bent." For each animal, multiple composite micrographs were assessed (at least 10 per animal) to obtain the number of Hoechst-stained nuclei and PC with their associated centriole from luminal alveolar cells and total (epithelial and myoepithelial) in alveolar and stromal compartments. The micrographs were analyzed for percentage of ciliated cells (represented as counterstained nuclei), and the incidence and percentage of bent, deflected, or nondeflected PC.

\section{Quantitative Real-Time Reverse-Transcription PCR Analysis}

Total RNA was isolated from $100 \mathrm{mg}$ of pulverized alveolar tissue using TRIzol according to the manufacturer's instructions (Invitrogen, Carlsbad, CA) and purified using an RNeasy kit (Qiagen, Valencia, CA). Total RNA was quantified using a Nanodrop 1000 spectrophotometer (Nanodrop, Wilmington, DE) and RNA integrity was measured on an Agilent 2100 Bioanalyzer (Agilent, Santa Clara, CA) with an RNA integrity number (RIN) $>7$ considered sufficient for real-time reverse transcription (RT)-PCR analysis. The conversion of RNA to cDNA was carried out using the SuperScript III reverse transcription kit (Life Technologies) according to the manufacturer's instructions. Each cDNA sample was assayed in triplicate by quantitative RT-PCR with SYBR Premix ExTaq System (Takara Bio Inc., Shiga, Japan) using a Corbett Thermocycler (Corbett Life Science, Qiagen, Venlo, the Netherlands). Each assay included RT-negative and no-template control reactions. The RT-PCR assays were performed under the following conditions: initially $95^{\circ} \mathrm{C}$ for $3 \mathrm{~min}$, followed by 40 cycles of $95^{\circ} \mathrm{C}$ for $10 \mathrm{~s}, 60^{\circ} \mathrm{C}$ for $20 \mathrm{~s}$, and $72^{\circ} \mathrm{C}$ for $20 \mathrm{~s}$. After the last cycle of each RT-PCR experiment, a dissociation curve was obtained starting at $72^{\circ} \mathrm{C}$, followed by a continuous temperature increase of $1^{\circ} \mathrm{C}$ increments every $30 \mathrm{~s}$ until $95^{\circ} \mathrm{C}$ was reached. All primers were used at a final concentration of 100 $\mathrm{n} M$ in each $10-\mu \mathrm{L}$ RT-PCR reaction. Genes used as endogenous controls were glyceraldehyde 3 -phosphate dehydrogenase, ubiquitin, and cyclophilin A. The primer sequences and assay conditions are outlined in Table 1. The PCR products were QIAquick columnpurified (Qiagen) and verified by DNA sequencing (DNA Sequencing Facility, University of Canterbury, New Zealand). Following RT-PCR, average take-off values for reference genes and genes of interest were generated for each sample using the Rotor-Gene Q software (version 2.1.0, Qiagen GmbH, Hilden, Germany). Relative quantification of gene expression was performed using comparative quantification to analyze changes in gene expression in a given sample relative to the lactating group. The amount of gene of interest in each sample was normalized to the geometric mean of the mRNA abundance of the 3 endogenous control genes and the resulting values were $\log _{10}$-transformed before statistical analysis. Averages for each treatment group were back-transformed and results were expressed as the fold-change relative to the control sample. 
Table 1. Sequences of PCR primers (forward and reverse), primer position, and PCR product sizes of bovine nucleic acid sequences used for investigating gene expression by real-time reverse transcription-PCR

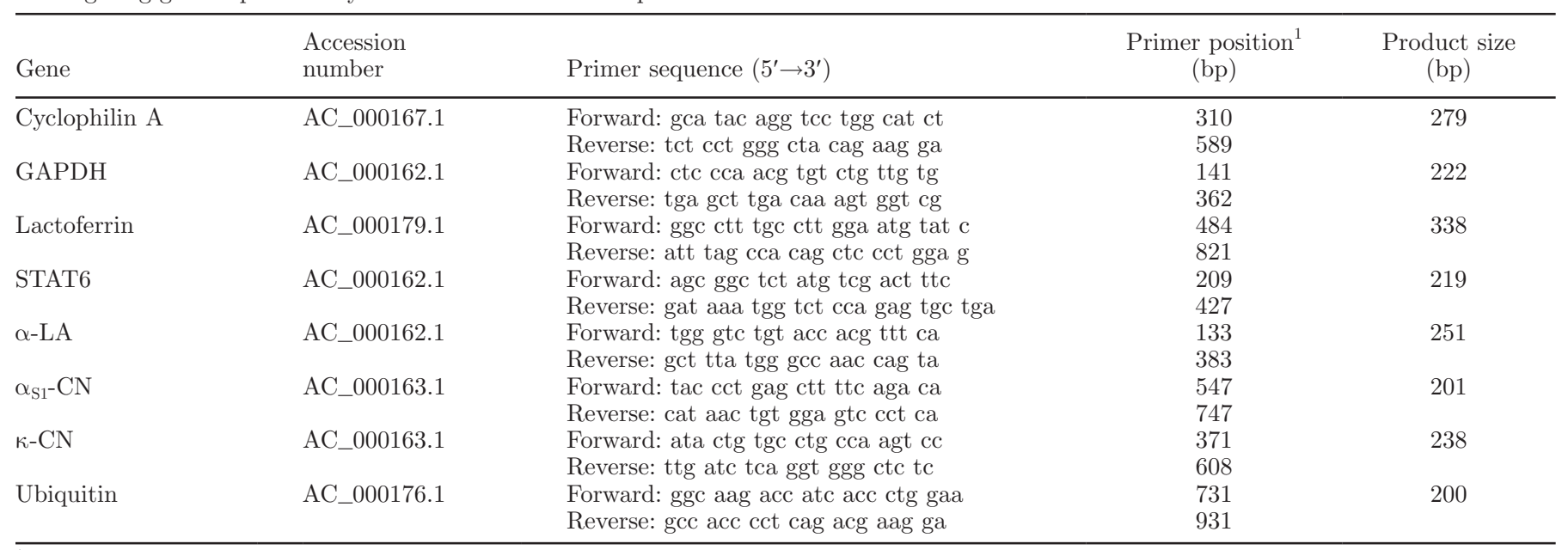

${ }^{1}$ Refers to the $5^{\prime}$ position of the primers in the nucleic acid sequence.

\section{Western Blot Analysis}

Protein was isolated from mammary alveolar tissue and the concentration determined as described previously (McMahon et al., 2004), with minor modifications. The total homogenate fraction was extracted in $1 \mathrm{~mL}$ of low-salt buffer containing 1\% Nonidet-P40 detergent and protease inhibitors and centrifuged at $10,000 \times g$ for $30 \mathrm{~min}$ at $4^{\circ} \mathrm{C}$ and the supernatant was collected as the soluble protein fraction for STAT6 analysis. Samples were mixed with $2 \times$ Laemmli loading buffer $[62.5 \mathrm{~m} M$ Tris $\mathrm{pH} 6.8,2 \%$ (wt/vol) SDS, $5 \%$ (vol/vol) $\beta$-mercaptoethanol, and $10 \%$ (vol/vol) glycerol; Laemmli, 1970], boiled for $5 \mathrm{~min}$, and stored at $-20^{\circ} \mathrm{C}$. Protein concentration was determined using Qubit 2.0 Fluorometer in conjunction with the Qubit Protein Assay kit (Invitrogen). Twenty micrograms of protein was separated on 10\% NuPAGE Novex Bis-Tris protein gels (Life Technologies) and replicate gels were stained with Coomassie blue to indicate uniformity of loading. Protein was transferred onto Hybond-ECL nitrocellulose membranes (Amersham Biosciences, Amersham, UK) using the Trans-Blot Cell (Bio-Rad Laboratories, Hercules, CA) wet blotting system. Blocking of nonspecific binding was achieved by immersing the membrane in $4 \%$ (wt/vol) nonfat milk powder for $2 \mathrm{~h}$ at room temperature on a rocker. Subsequently, membranes were probed with the STAT6 primary antibody (1:1,000; Pierce, Waltham, MA) overnight at $4^{\circ} \mathrm{C}$ on a rocker, followed by incubation with horseradish peroxidase-conjugated secondary antibodies (goat-antirabbit, homemade, 1:10,000) for $1 \mathrm{~h}$ at room tempera- ture. Membranes were washed in multiple changes of wash buffer [Tris-buffered saline, $0.1 \%$ (vol/vol) Tween 20, $0.1 \%$ (wt/vol) BSA], following each antibody incubation. Immunoreactive protein bands were detected using a chemiluminescence system (Amersham ECL Western Blotting Detection Reagents; GE Healthcare Life Sciences, Cleveland, OH), BioMax XAR film (Kodak, Rochester, NY), and the 100 Plus film processor (AllPro Imaging, Melville, NY). The developed films were scanned using a GS-800 densitometer (Bio-Rad Laboratories) and analyzed using the Quantity One software (version 4.6.6; Bio-Rad Laboratories). Commercially available STAT6 293T transfected lysate (Abcam, Cambridge, UK) was used as positive control to determine STAT6 protein detection (data not shown).

\section{Statistical Analysis}

Data on PC acquired from composite micrographs were analyzed as a binomial distribution by GenStat (16th ed., version 16.1.0.10916; 64-bit version; GenStat Co., Hemel Hempstead, UK) to allow cow effects to be factored in. Differences in levels of mRNA expression from each group were analyzed using the Student's paired $t$-test with a 2-tailed distribution (Excel, 2010; Microsoft Corp., Redmond, WA). Densitometry data from Western blotting were $\log _{10}$-transformed and analyzed by ANOVA in GenStat with blocking on replicate and adjusting for between-gel variations to detect differences between control (lactating) and treatment samples (7-d NM and 28-d NM). Data are expressed as mean \pm SEM. 


\section{RESULTS}

\section{Histological Analysis of Lactating and Involuting Mammary Gland}

Before fluorescent immunohistochemistry, histological morphology was assessed to define the lactating appearance of the tissue within each group (Figure 1, panels A to F). For the lactating control group, a similar histological appearance was observed, with no marked evidence of between-animal variation. They all presented large uniform areas of moderately sized, open alveoli surrounded by cuboidal SEC with a small amount of interalveolar stromal tissue observed throughout the tissue. At low magnification, the alveoli appeared to be of similar size and were open and relaxed; that is, not distended (Figure 1A). Furthermore, the alveoli were made up of a single SEC layer surrounding each lumen, and a small amount of accumulated milk product was detected within some lumina, apparent as light- to dark-stained acellular material. Minimal variation in size of alveoli and thickness of alveolar cell layers was observed across all alveoli. At higher magnification, the alveolar cell layers appeared intact without any obvious signs of disruption of the highly ordered alveolar structure (Figure 1B). The majority of the tissue section was dominated by an open alveolar structure with a minor interalveolar connective tissue component, although a few thick bands of stromal tissue that encompassed multiple lobules were observed.

After 7-d NM (Figure 1C and D), the majority of alveoli appeared larger and engorged with accumulated milk compared with the control group (Figure 1A and B). At low magnification, both inter-and intra-animal variations were observed. Some samples displayed more histological features associated with active lactation, and others exhibited early signs of involution, whereas all animals showed considerable intralobular heterogeneity. Although most alveoli were large with a stretched morphology, a few localized, collapsed areas were apparent. These were characterized by smaller alveoli with a "ruffled" appearance due to accumulation of vesicle-engorged alveoli (VEA) within the epithelial cells (Figure 1C). The VEA are also referred to as vacuole-containing alveoli; that is, alveoli with large vacuoles containing fat droplets and material from secretory vesicles present within SEC and high numbers of vesicles containing coalescing fat droplets and proteins present in the alveolar lumen. Almost all alveoli contained accumulated milk product, and large milk vesicles were present within some lumina (Figure $1 \mathrm{C}$ and D). At higher magnification, large VEA were present within SEC and high numbers of VEA were detected in the alveolar lumen (Figure 1D).
Although inter-animal variation was observed for the 28-d NM group, the majority of tissue was dominated by a nonlactating appearance (Figure $1 \mathrm{E}$ and $\mathrm{F}$ ). This was characterized by collapsed alveoli, abundance of large vesicles within SEC and alveolar lumens, thickened areas of stromal tissue between alveoli, and broad bands of supportive connective tissue containing adipocytes. Infiltration of the highly involuted tissue with leukocytes resulted in a highly cellular appearance and made it difficult to distinguish alveolar boundaries. At higher magnification, the majority of alveoli were collapsed with ruffled edges, cells protruded into the lumen, and discernible gaps occurred between adjacent cells (Figure 1F).

\section{Qualitative Analysis of Distribution, Appearance, and Orientation of PC in Mammary Tissue}

Figure 2 shows representative composite images of immunofluorescent-labeled PC in alveolar tissue with examples of straight, bent, and deflected to lie more parallel to the apical cell surface. During active lactation, the alveolar PC projected from the apical side of the luminal SEC into the luminal space. Most PC were short, although predictions of the exact $\mathrm{PC}$ length could not be made due to the slicing process during tissue sectioning. Some cilia were bent (example in Figure $2 \mathrm{~A}$ ), whereas others were straight and projected into the luminal space at various orientations and angles (example in Figure 2B). Their associated centriole was commonly detected close to the nuclei, enabling the PC cell of origin to be identified. In sections with many PC and surrounding tissue, the alveolar structure and cells of PC origin were more difficult to interpret. The PC were also detected in underlying MEC projecting into the interalveolar space. In distended alveoli (indicated by widely spaced nuclei), the PC were often deflected or bent to lie more parallel to the alveolar wall, suggesting a potential deflection against the apical cell surface (example in Figure 2C).

Similar results were observed for the 7-d NM group compared with the lactating control animals. In accordance with the histological analysis (Figure 1), the majority of the alveoli appeared to be open, and the PC and their cells of origin could be identified. As described for the controls, some cilia appeared to be bent (Figure 2A), whereas others were straight and projected into the luminal space at various orientations and angles (Figure 2B). Increased amounts of stromal connective tissue at this stage were reflected by increased numbers of PC associated with SFC within the interalveolar space. The SFC within the interalveolar space were easily detected due to the proximity of their associated centrioles and the nuclei. 
40x

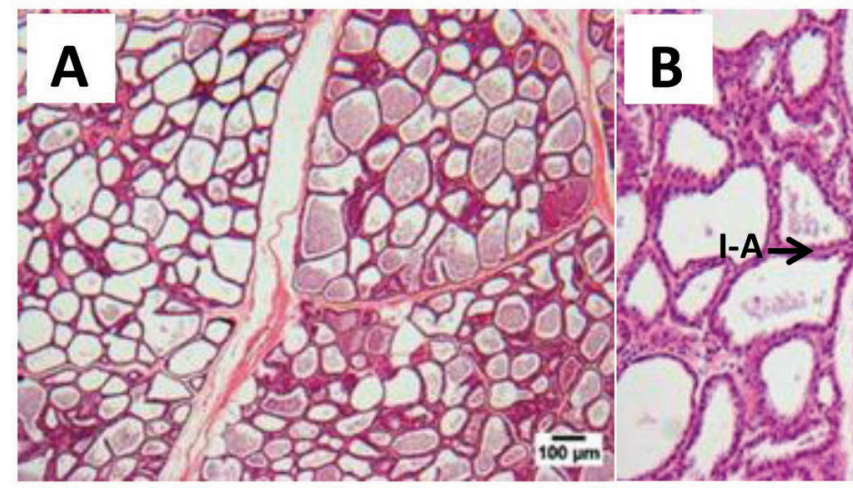

100x

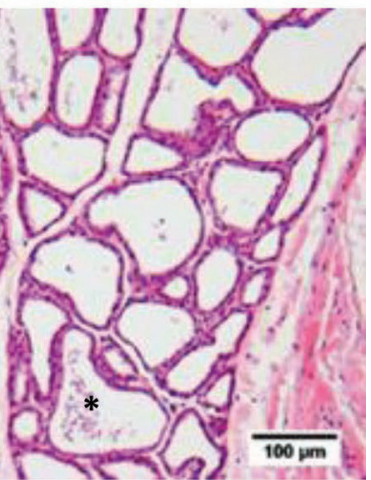

7-d NM

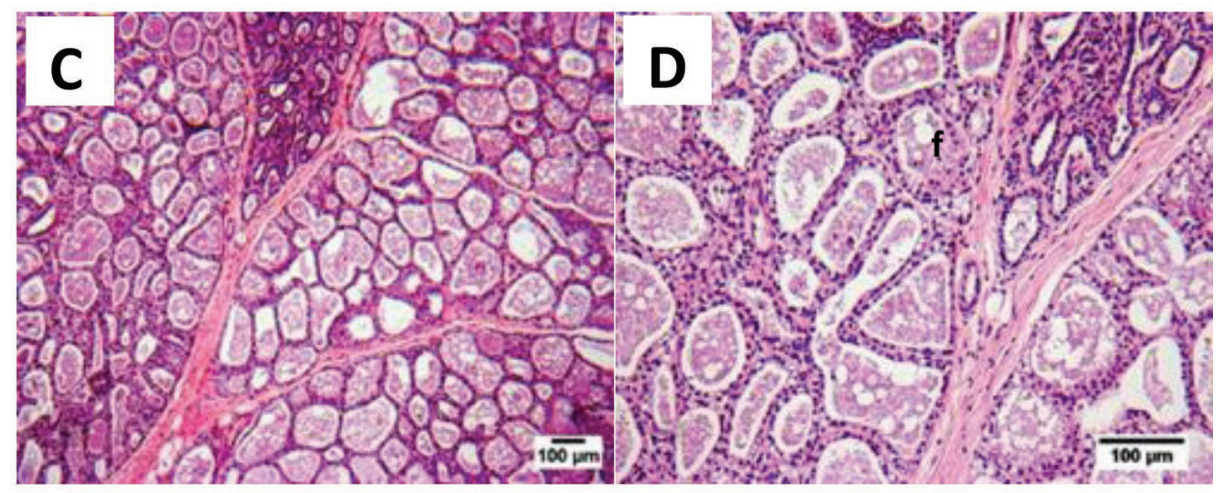

28-d NM

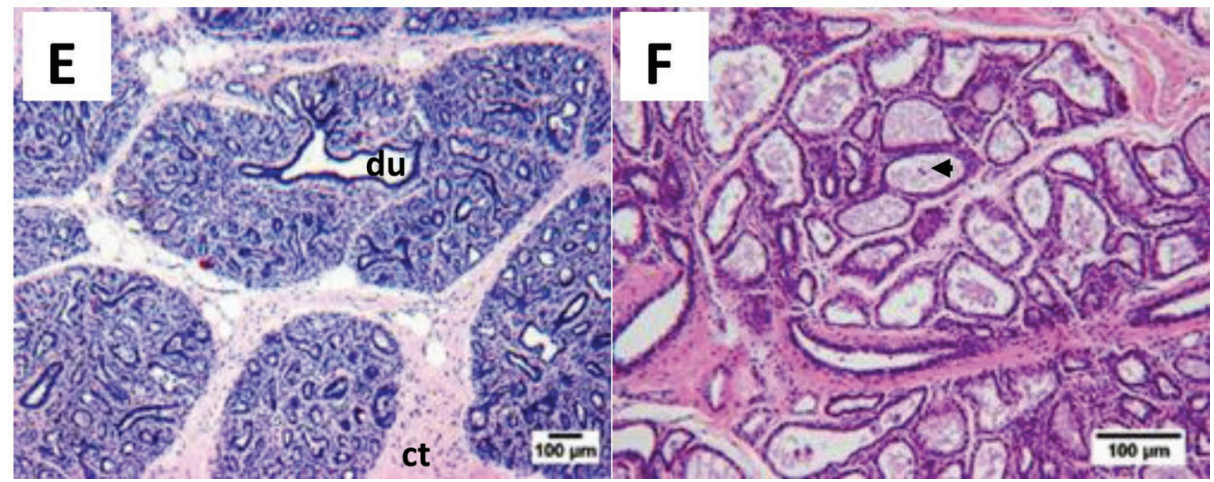

Figure 1. Representative images of hematoxylin and eosin-stained sections of mammary alveolar tissue from the lactating (control) group (A, B), the 7-d nonmilked (NM) group (C, D), and the 28-d NM group (E, F). Examples of ducts (du), fat cells (f), luminal contents (*), interalveolar stroma (I-A), connective tissue (ct), and leukocytes (arrowhead) are shown. Images A, C, and E: 40×; images B, D, and F: 100×. Scale bars are $100 \mu \mathrm{m}$. Color version available online.

After a 28-d period of NM, more alveoli appeared to be collapsed compared with the control and 7-d NM groups. Consequently, increased connective tissue was present at this stage, which resulted in an increase of background autofluorescence compared with the other 2 groups. Of the clearly interpretable images, $\mathrm{PC}$ were observed in SEC and MEC, and PC appearance and orientation were similar to that observed in the other 2 groups. However, fewer PC appeared to project into the luminal space, instead lying flat against the apical cell surface (example in Figure 2C) or projecting toward the interalveolar space (Figure 2C). Moreover, the cell of origin could not always be identified and thus the PC were not counted. With the increase in connective tissue, more PC were observed within SFC of the interlobular stromal tissue and appeared to orientate in parallel with the axis of the stromal collagen network. 

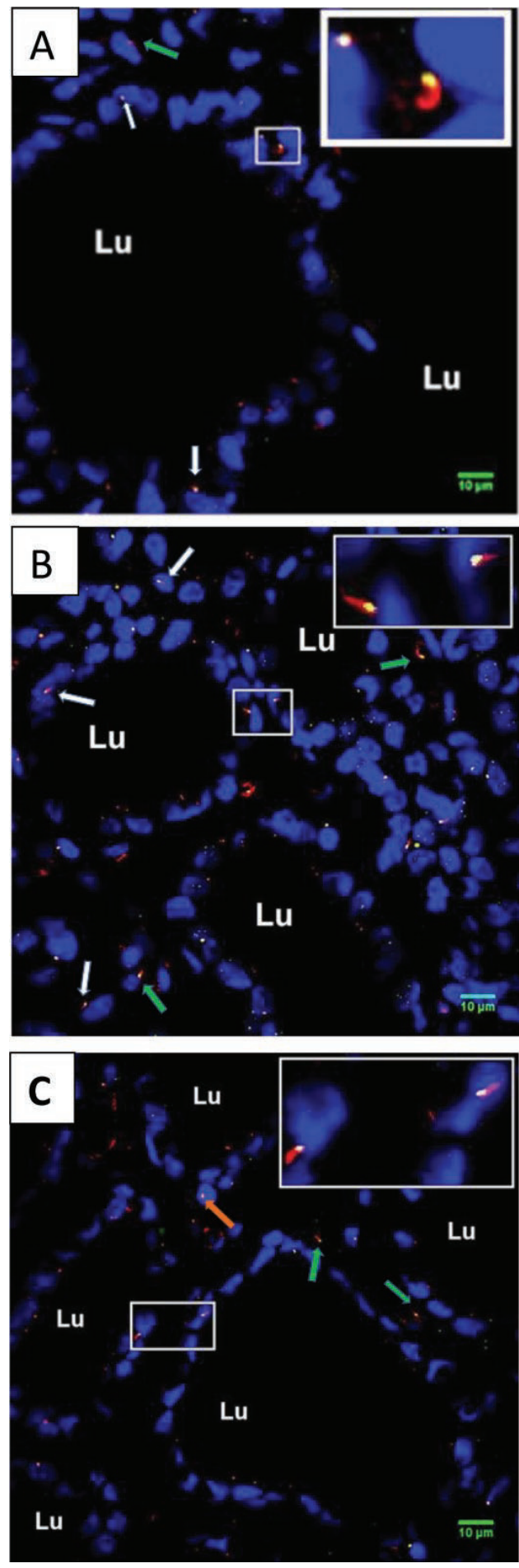

Figure 2. Representative composite images demonstrating bend (A), straight (B), and deflected (C) primary cilia (PC) in alveolar tissue sections. The PC were identified by green basal body/centriole staining (appears yellow when all layers are merged) and co-localization with red axoneme staining close to the blue-stained nuclei of the alveoli. White lines indicate areas of enlargement. White arrows show examples of PC on secretory epithelial cells. Green arrows show examples of $\mathrm{PC}$ in the underlying stromal tissue. Orange arrow shows an example of PC projecting toward the underlying stromal. $\mathrm{Lu}=$ luminal space. Scale bars are $10 \mu \mathrm{m}$.

\section{Quantitative Analysis of PC Incidence and Orientation}

Overall, the longer the period of nonmilking, the more tissue (represented by stained nuclei) was present per unit area due to the increase in collapsed alveoli (Figure 1). Consequently, more PC were detected in the 7-d NM and 28-d NM groups in both the total (alveolar and stromal compartments) and luminal (SEC and MEC) fractions compared with that in mid lactation (Figure 3). In the 28-d NM group, we observed fewer ( $P$ $<0.05) \mathrm{PC}$ in the luminal fraction relative to the total fraction, consistent with rapidly increasing numbers of SFC (Figure 3). The percentage of ciliated cells in the luminal fraction increased in the 7 -d NM $(P<0.1)$ and 28 -d NM $(P<0.05)$ groups relative to the luminal fraction at lactation (Figure 4). In the total fraction, the percentage of ciliated cells was the same in the lactation and 7-d NM groups, but was increased $(P<$ 0.1 ) in the 28-d NM group compared with the lactation group (Figure 4). Nevertheless, the average depth of Z-stacks was $1.5 \mu \mathrm{m}$, whereas the tissue sections were $7 \mu \mathrm{m}$, both considerably less than the average width of a luminal SEC (Millier et al., 2013). Therefore, the proportion of cilia detected will most likely underestimate the actual biological incidence.

All PC appearances and orientations were recorded throughout all composite images (Figure 5). Furthermore, different $\mathrm{PC}$ orientations were detected within the same alveolus (Figure 2B). Only PC with clearly

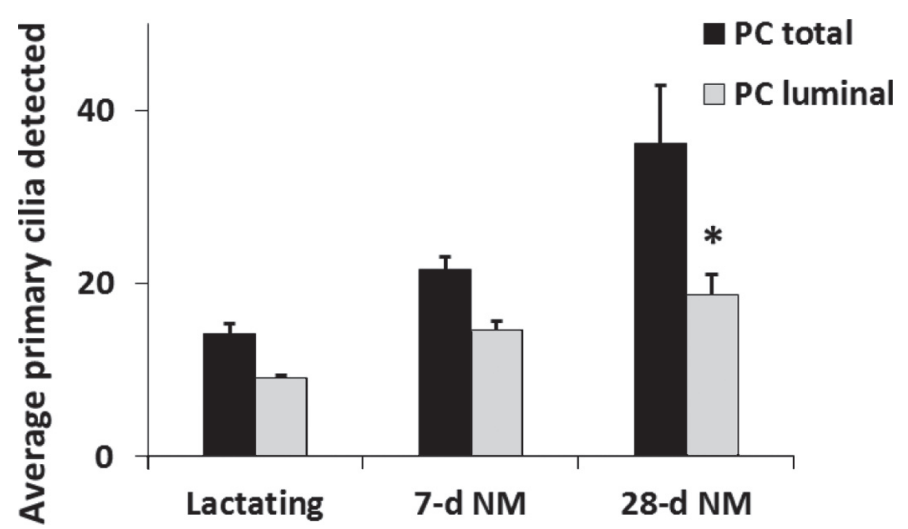

Figure 3. Luminal [secretory epithelial cells (SEC) and myoepithelial cells (MEC)] and total [SEC, MEC, and stromal fibroblast cells (SFC)] primary cilia (PC) within lactating control, 7-d nonmilked (NM), and 28-d NM groups. Following immunofluorescent staining of PC, each tissue section was divided into 10 equal-sized areas. Per area, at least one alveolus was imaged and composite micrographs were created. Multiple composite micrographs were assessed (at least 10 per animal) from multiple tissue sections from each animal and analyzed for total PC count and luminal PC count. Luminal PC increased slightly compared with a large increase in total PC, reflecting increased numbers of SFC as stromal tissue mass increased. Data are presented as mean $\pm \mathrm{SEM} ;{ }^{*} P<0.05$ 
visible axonemes, basal bodies, and associated nuclei in proximity were analyzed. In all treatment groups, the number of bent PC was low compared with the numbers of PC deflected against the luminal cell surface and $\mathrm{PC}$ projecting directly into the lumen (Figure 5).

\section{Milk Protein and STAT6 Levels Following Extended Periods of Nonmilking}

The $\alpha_{S_{1}}$-casein mRNA levels were reduced 42 - and 16 -fold $(P<0.01)$ for the 7 -d NM and 28 -d NM groups, respectively, compared with lactating controls (Figure $6)$. Similarly, mRNA levels of $\alpha$-LA declined 157- and 27 -fold $(P<0.01)$, respectively, and that of $\kappa$-casein declined by 5 - and 8-fold, respectively, following 7-d NM and 28-d NM compared with controls $(P<0.01$; Figure 6). In contrast, lactoferrin mRNA levels increased 5-fold by 7-d NM compared with lactation, although this was not statistically significant. By $28-\mathrm{d}$ $\mathrm{NM}$, lactoferrin mRNA tended to be increased $(P<$ 0.1) 7-fold compared with lactating controls (Figure 6).

Although we detected an overall numerical increase in mRNA levels of STAT6 following 7-d NM and 28-d NM, by 3-and 10-fold, respectively, no significant change was detected (Figure 6). The protein levels of STAT6 increased numerically by 1.7 -fold following 7 -d NM and increased $(P<0.01)$ by 3.8 -fold following $28-\mathrm{d}$ NM relative to the lactating control (Figure 7A and B).

\section{DISCUSSION}

Mammary tissue is composed of different tissues and cell types, and mammary gland function is tightly coordinated by various factors and stimuli, both systemic and local. Moreover, the optimal development

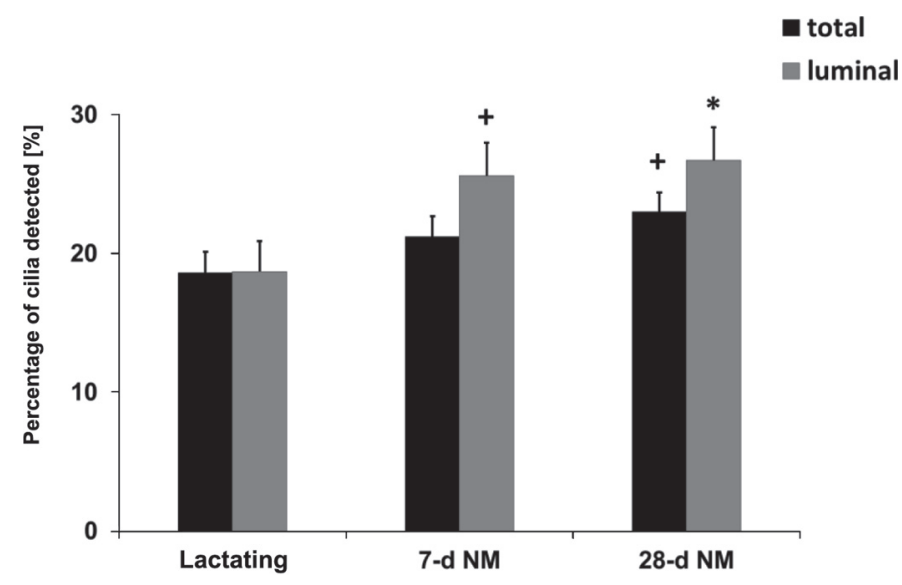

Figure 4. Percentage of ciliated cells (total and luminal fractions) detected within lactating control, 7-d nonmilked (NM), and 28-d NM groups. Data are presented as mean $\pm \mathrm{SEM} ;{ }^{*} P<0.05,{ }^{+} P<0.1$ relative to lactating control group.

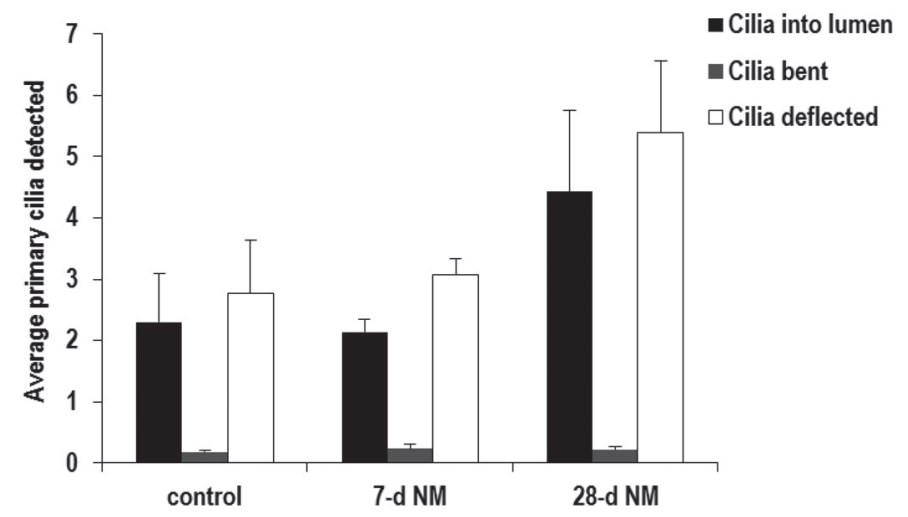

Figure 5. Different primary cilia (PC) morphologies detected within lactating control, 7-d nonmilked (NM), and 28-d NM groups. Using composite micrographs, clearly visible PC were classified as bent, deflected, or projecting toward the lumen in accordance with their appearance and orientation. Data are presented as mean \pm SEM.

of the highly organized lobular-alveolar structures is important to ensure sufficient milk production to nurse the offspring (Knight and Peaker, 1982; Plath et al., 1997). After weaning in most mammalian species, however, extensive tissue remodeling occurs to prepare the mammary gland for a subsequent pregnancy-lactationinvolution cycle (Anderson et al., 2007).

For the dairy cow, the majority of the alveolar structure remains intact during involution. However, it is proposed that senescent cells are replaced by mammary progenitor cells to ensure sufficient milk yield in the subsequent lactation period (Capuco and Akers, 1999; Capuco et al., 2003). In the present study, the overall structure of the mammary gland remained visible in all 3 treatment groups. However, heterogeneity in the tissue structures was observed. As previously described (Molenaar et al., 1992), within the same animal, there were areas of lobules showing signs of active lactation, whereas other areas appeared to be involuted. Nonetheless, with longer periods of nonmilking, more collapsed alveoli were observed and the overall tissue structure appeared less organized.

In mice, insufficient clearance of cell debris or milk constituents is thought to lead to tissue scarring and reduced milk production in subsequent lactations (Atabai et al., 2005). Furthermore, locally secreted cytokines are important for controlling lineage commitment during pregnancy as well as controlling and coordinating cell death and tissue remodeling during involution (Watson and Kreuzaler, 2011). Although there is a growing body of knowledge in regulatory aspects of milk production and maintenance (Wilde et al., 1995; Accorsi et al., 2002; Singh et al., 2008), the question of how these stimulatory factors mediate a local cellular response remains unanswered. 
Recently, the primary cilium has emerged as a cellular mechanosensor found in numerous tissues, such as bone (Nguyen and Jacobs, 2013), liver (Masyuk et al., 2008), kidney (Praetorius and Spring, 2001), and lungs (Ellerman and Bisgaard, 1997), sensing not only fluid flow (Schwartz et al., 1997) but also mechanical signals, such as tension and pressure (Poole et al., 1985) and touch and vibration (Singla and Reiter, 2006; Hoey et al., 2012). Furthermore, PC and their role as potential mechanosensors have been linked to mammary gland development in mice (McDermott et al., 2010). However, their role in mammary gland involution remains elusive. To our knowledge, only 2 previous studies have investigated and described PC in the bovine mammary gland during and after lactation (Nickerson, 1989; Millier et al., 2013). In agreement, the present study shows that PC are present on both luminal SEC and MEC in the bovine mammary gland. However, the overall number of ciliated SEC was low. Furthermore, the number of SEC ciliated during active lactation was lower than SEC ciliated following extended periods of nonmilking. Similar observations have been reported previously (Nickerson, 1989; McDermott et al., 2010; Millier et al., 2013). In fact, in the mouse mammary gland, PC numbers decreased once mammary gland tissue was fully developed (McDermott et al., 2010). During active lactation, the epithelial cell layer becomes fully differentiated and highly metabolically active (Larson, 1985), and it has been postulated that a state of high secretion may not be compatible with maintaining a PC (Millier et al., 2013). Furthermore, during lactation, the epithelial cell layer is maintained by a complex network
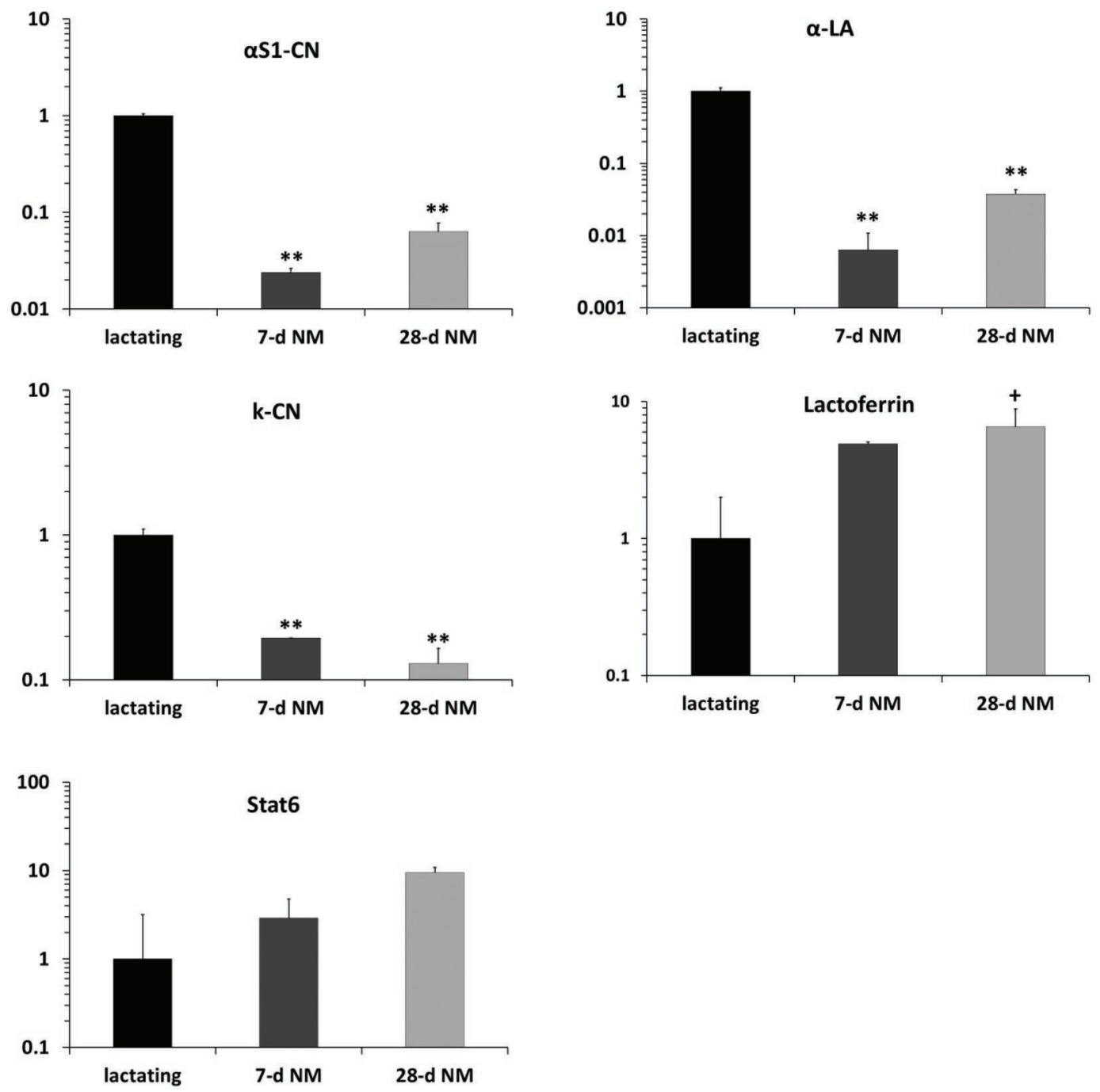

Figure 6. Changes in mRNA levels of $\alpha_{\mathrm{S}_{1}} \mathrm{CN}, \alpha-\mathrm{LA}, \kappa-\mathrm{CN}$, lactoferrin, and signal transducer and activator of transcription (STAT) 6 following extended periods of nonmilking (7- and 28-d NM). Data from each group were expressed as back-transformed fold-change relative to lactation. Data are presented as mean $\pm \mathrm{SEM} ;{ }^{* *} P<0.01,{ }^{+} P<0.1$. 


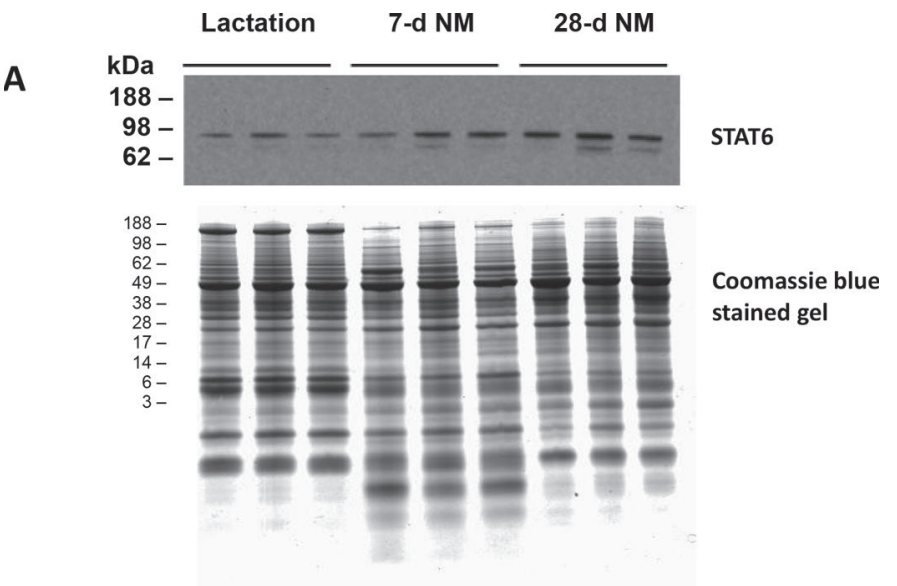

B

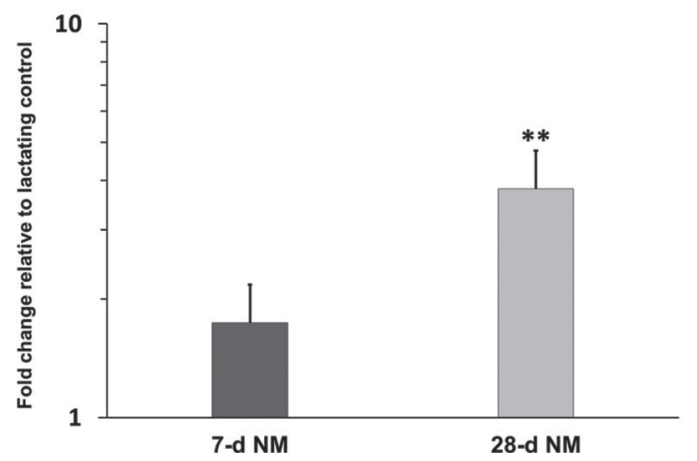

Figure 7. (A) Representative image of Western blot to determine patterns of signal transducer and activator of transcription (STAT)6 protein following extended periods of nonmilking (7- and 28-d NM). Each lane was loaded with $20 \mu \mathrm{g}$ of total protein. Replicate gels were stained with Coomassie blue to indicate uniformity of loading. Molecular masses $(\mathrm{kDa})$ are indicated to the left of the panel. The primary antibody used was rabbit anti-STAT6 (polyclonal, 1:1,000 dilution). (B) Densitometric analysis of Western blots to determine changes in STAT6 protein in the mammary gland following 7- and 28-d NM. Results are graphed as back-transformed mean fold changes relative to the control, and data are presented as mean $\pm \mathrm{SEM} ;{ }^{* *} P$ $<0.01$.

of cell-cell and cell-matrix interactions, including tight junctions and integrin-mediated focal adhesions, each playing an important role during cell communication (Chen et al., 2004). Thus, there may not be a need for every cell to be ciliated to achieve synchronized milk secretion once fully differentiated.

In the lactating mammary gland, the majority of the secreted milk is stored in the alveolar compartment, which in turn leads to fluid accumulation and intramammary pressure increase (Peaker, 1980; Bruckmaier, 2005). In SEC and MEC, PC are exposed to the extracellular environment, in this case the fluid-filled alveolar lumen, where they could act as sensors for pressure dynamics in the mammary alveoli or for fluid flow in the mammary ducts during milk removal. Therefore, it was not surprising to see more PC deflected flat against the apical cell surface rather than projecting toward the lumen. During milk stasis, however, no milk is removed from the mammary gland, which leads to the absence of fluid flow and, thus, no PC bending. In the absence of fluid flow, the proteolytically cleaved carboxy-terminal region of $\mathrm{PC}-1$ translocates to the nucleus, where it associates with the transcription factor STAT6 and the co-activator p100 to stimulate gene expression (Low et al., 2006; Berbari et al., 2009). The STAT6 transcription factor and its upstream cytokines IL-4 and IL-13 appear to play a role during the expansion of the luminal lineage as well as postlactational tissue regression and are linked to PC signaling (Khaled et al., 2007; Zhang et al., 2008; O'Brien et al., 2010, 2012; Hughes and Watson, 2012). Furthermore, previously shown to be upregulated during lactation (Broadhurst and Wheeler, 2001), the p100 co-activator has also been identified as a promoter of cell growth (Tong et al., 1995) and forms a stable complex with PC-1, which is sequestered at the PC (Nauli et al., 2003).

In this study, extended periods of nonmilking resulted in the onset of early involution (as indicated by gene expression and histology described above) in the bovine mammary gland. Moreover, there was a significant increase in STAT6 protein abundance, but the phosphorylation status of STAT6 was not determined. Therefore, no conclusions on STAT6 activation status following extended periods of nonmilking can yet be made. Although the STAT6 transcription factor is important for commitment of luminal epithelial cells to the alveolar lineage in mammary gland development (Khaled et al., 2007; McDermott et al., 2010), it has also been linked to the immune system by playing a role in the differentiation of T-helper cells (Hughes and Watson, 2012). Furthermore, the STAT6 transcription factor is activated by a small group of cytokines, mainly IL-4 and IL-13 (Bromberg, 2000, Haricharan and $\mathrm{Li}, 2014)$. Previously, IL-4 and IL-13 have been shown to act as macrophage chemoattractants (Hiester et al., 1992) and to induce an alternative M2 form of macrophage activation (Gordon, 2003), which is involved in wound healing and tissue remodeling and repair (O'Brien et al., 2010). In the mouse mammary gland, gene expression profiling during postlactational tissue regression showed an increase in genes previously linked to the immune system (Clarkson et al., 2004), which coincides with increasing levels of IL-4 and IL13 potentially acting as macrophage chemoattractants (O'Brien et al., 2010).

\section{CONCLUSIONS}

Results of this study indicate a potential role for PC as mechanosensors in the bovine mammary gland. Assessment of histological features as well as decreased 
milk protein gene expression levels showed an overall increase in the degree involution and several key features associated with involution at both 7 -d and 28-d NM. Furthermore, extended periods of nonmilking resulted in an increase in ciliated SEC, which could be an indicator of epithelial cell dedifferentiation, reassembling of their PC for correct mammary gland development, and, thus, replacement of senescent cells in preparation for the next lactation period. Finally, extended periods of nonmilking resulted in an increase in STAT6 protein abundance. In the absence of fluid flow (i.e., milk stasis), STAT6 transcription factor activation could stimulate IL-4 and IL-13 gene expression. This results in a feedback loop with IL-4 and IL-13 inducing further STAT6 gene expression as well as acting as chemoattractants for macrophages to promote tissue remodeling and to clear the gland of cell debris and milk constituents.

\section{ACKNOWLEDGMENTS}

The authors thank H. Henderson (AgResearch Ltd., Hamilton, New Zealand) for assistance with the statistical analysis, J. Dobson (AgResearch) for initial analysis of milk protein genes, and M. Millier (University of Otago, Dunedin, New Zealand) for advice and guidance during immunofluorescent analysis. Financial support from the Ministry of Business, Innovation and Employment (MBIE; Wellington, New Zealand) is gratefully acknowledged. Furthermore, C. A. Poole was supported in part by a James Cook Research Fellowship from the Royal Society of New Zealand (Wellington, New Zealand).

\section{REFERENCES}

Abou Alaiwi, W. A., S. Lo, and S. Nauli. 2009. Primary cilia: Highly sophisticated biological sensors. Sensors (Basel) 9:7003-7020.

Accorsi, P. A., B. Pacioni, C. Pezzi, M. Forni, D. J. Flint, and E. Seren. 2002. Role of prolactin, growth hormone and insulin-like growth factor 1 in mammary gland involution in the dairy cow. J. Dairy Sci. 85:507-513.

Anderson, S. M., M. C. Rudolph, J. L. McManaman, and M. C. Neville. 2007. Key stages in mammary gland development. Secretory activation in the mammary gland: It's not just about milk protein synthesis! Breast Cancer Res. 9:204.

Atabai, K., R. Fernandez, X. Huang, I. Ueki, A. Kline, Y. Li, S. Sadatmansoori, C. Smith-Steinhart, W. Zhu, R. Pytela, Z. Werb, and D. Sheppard. 2005. Mfge8 is critical for mammary gland remodeling during involution. Mol. Biol. Cell 16:5528-5537.

Barnes, B. G. 1961. Ciliated secretory cells in the pars distalis of the mouse hypophysis. J. Ultrastruct. Res. 5:453-467.

Berbari, N. F., A. K. O'Connor, C. J. Haycraft, and B. K. Yoder. 2009. The primary cilium as a complex signaling center. Curr. Biol. 19:R526-R535.

Broadhurst, M. K., and T. T. Wheeler. 2001. The p100 coactivator is present in the nuclei of mammary epithelial cells and its abundance is increased in response to prolactin in culture and in mammary tissue during lactation. J. Endocrinol. 171:329-337.
Bromberg, J. 2000. Signal transducers and activators of transcription as regulators of growth, apoptosis and breast development. Breast Cancer Res. 2:86-90.

Bruckmaier, R. M. 2005. Normal and disturbed milk ejection in dairy cows. Domest. Anim. Endocrinol. 29:268-273.

Capuco, A. V., and R. M. Akers. 1999. Mammary involution in dairy animals. J. Mammary Gland Biol. Neoplasia 4:137-144.

Capuco, A. V., S. E. Ellis, S. A. Hale, E. Long, R. A. Erdman, X. Zhao, and M. J. Paape. 2003. Lactation persistency: Insights from mammary cell proliferation studies. J. Anim. Sci. 81:18-31.

Chen, C. S., J. Tan, and J. Tien. 2004. Mechanostransduction at cellmatrix and cell-cell contacts. Annu. Rev. Biomed. Eng. 6:275-302.

Clarkson, R. W., M. T. Wayland, J. Lee, T. Freeman, and C. J. Watson. 2004. Gene expression profiling of mammary gland development reveals putative roles for death receptors and immune mediators in post-lactational regression. Breast Cancer Res. 6:R92R109.

Collier, R. J., L. L. Hernandez, and N. D. Horseman. 2012. Serotonin as a homeostatic regulator of lactation. Domest. Anim. Endocrinol. 43:161-170.

Cooper, C., K. Stelwagen, K. Singh, V. C. Farr, C. G. Prosser, and S. R. Davis. 2004. Expression of the tight junction protein zonula occludens-1 during mammary engorgement. Proc. N.Z. Soc. Anim. Prod. 64:43-47.

Davis, S. R., V. C. Farr, and K. Stelwagen. 1999. Regulation of yield loss and milk composition during once-daily milking: A review. Livest. Prod. Sci. 59:77-94.

DuFort, C. C., M. J. Paszek, and V. M. Weaver. 2011. Balancing forces: Architectural control of mechanotransduction. Nat. Rev. Mol. Cell Biol. 12:308-319.

Ellerman, A., and H. Bisgaard. 1997. Longitudinal study of lung function in a cohort of primary ciliary dyskinesia. Eur. Respir. J. 10:2376-2379.

Gordon, S. 2003. Alternative activation of macrophages. Nat. Rev. Immunol. 3:23-35.

Haricharan, S., and Y. Li. 2014. STAT signaling in mammary gland differentiation, cell survival and tumorigenesis. Mol. Cell. Endocrinol. 382:560-569.

Hiester, A. A., D. R. Metcalf, and P. A. Campbell. 1992. Interleukin-4 is chemotactic for mouse macrophages. Cell. Immunol. 139:72-80.

Hoey, D. A., M. E. Downs, and C. R. Jacobs. 2012. The mechanics of the primary cilium: An intricate structure with complex function. J. Biomech. 45:17-26.

Hughes, K., and C. J. Watson. 2012. The spectrum of STAT functions in mammary gland development. JAK-STAT 1:151-158.

Janmey, P. A., and C. A. McCulloch. 2007. Cell mechanics: Integrating cell responses to mechanical stimuli. Annu. Rev. Biomed. Eng. $9: 1-34$.

Jones, T. J., and S. M. Nauli. 2012. Mechanosensory calcium signaling. Adv. Exp. Med. Biol. 740:1001-1015.

Khaled, W. T., E. K. Read, S. E. Nicholson, F. O. Baxter, A. J. Brennan, P. J. Came, N. Sprigg, A. N. McKenzie, and C. J. Watson. 2007. The IL-4/IL-13/Stat6 signalling pathway promotes luminal mammary epithelial cell development. Development 134:27392750 .

Knight, C. H., and M. Peaker. 1982. Development of the mammary gland. J. Reprod. Fertil. 65:521-536.

Laemmli, U. K. 1970. Cleavage of structural proteins during the assembly of the head of bacteriophage T4. Nature 227:680-685.

Larson, B. L. 1985. Biosynthesis and cellular secretion of milk. Pages 129-163 in Lactation. B. L. Larson, ed. Iowa State University Press, Ames.

Low, S. H., S. Vasanth, C. H. Larson, S. Mukherjee, N. Sharma, M. T. Kinter, M. E. Kane, T. Obara, and T. Weimbs. 2006. Polycystin-1, STAT6, and P100 function in a pathway that transduces ciliary mechanosensation and is activated in polycystic kidney disease. Dev. Cell 10:57-69.

Mallah, G. S., J. Dobson, S. Moon, H. Henderson, A. J. Molenaar, J. Guan, and K. Singh. 2013. The effect of re-milking following extended non-milking periods on the proliferation and apoptosis 
of mammary epithelial cells in dairy cows. Proc. N.Z. Soc. Anim. Prod. 73:51-53.

Masyuk, A. I., T. V. Masyuk, and N. F. LaRusso. 2008. Cholangiocyte primary cilia in liver health and disease. Dev. Dyn. 237:2007-2012.

McDermott, K. M., B. Y. Liu, T. D. Tlsty, and G. J. Pazour. 2010. Primary cilia regulate branching morphogenesis during mammary gland development. Curr. Biol. 20:731-737.

McMahon, C. D., V. C. Farr, K. Singh, T. T. Wheeler, and S. R. Davis. 2004. Decreased expression of $\beta 1$-integrin and focal adhesion kinase in epithelial cells may initiate involution of mammary glands. J. Cell. Physiol. 200:318-325.

Millier, M. J., K. Singh, and C. A. Poole. 2013. Characterization of primary cilia distribution and morphology during lactation, stasis, and involution in the bovine mammary gland. Anat. Rec. (Hoboken) 296:1943-1953.

Molenaar, A. J., S. R. Davis, and R. J. Wilkins. 1992. Expression of alpha-lactalbumin, alpha-S1-casein, and lactoferrin genes is heterogeneous in sheep and cattle mammary tissue. J. Histochem. Cytochem. 40:611-618.

Na, S., O. Collin, F. Chowdhury, B. Tay, M. Ouyang, Y. Wang, and N. Wang. 2008. Rapid signal transduction in living cells is a unique feature of mechanotransduction. Proc. Natl. Acad. Sci. USA 105:6626-6631.

Nauli, S. M., F. J. Alenghat, Y. Luo, E. Williams, P. Vassilev, X. Li, A. E. Elia, W. Lu, E. M. Brown, S. J. Quinn, D. E. Ingber, and J. Zhou. 2003. Polycystins 1 and 2 mediate mechanosensation in the primary cilium of kidney cells. Nat. Genet. 33:129-137.

Nguyen, A. M., and C. R. Jacobs. 2013. Emerging role of primary cilia as mechanosensors in osteocytes. Bone 54:196-204.

Nickerson, S. C. 1989. Cilia on bovine mammary epithelium: Ultrastructural observations. Cell Tissue Res. 255:675-677.

O’Brien, J., T. Lyons, J. Monks, M. S. Lucia, R. S. Wilson, L. Hines, Y. G. Man, V. Borges, and P. Schedin. 2010. Alternatively activated macrophages and collagen remodeling characterize the postpartum involuting mammary gland across species. Am. J. Pathol. 176:1241-1255.

O'Brien, J., H. Martinson, C. Durand-Rougely, and P. Schedin. 2012. Macrophages are crucial for epithelial cell death and adipocyte repopulation during mammary gland involution. Development 139:269-275.

Olsan, E. E., S. Mukherjee, B. Wulkersdorfer, J. M. Shillingford, A. J. Giovannone, G. Todorov, X. Song, Y. Pei, and T. Weimbs. 2011. Signal transducer and activator of transcription-6 (STAT6) inhibition suppresses renal cyst growth in polycystic kidney disease. Proc. Natl. Acad. Sci. USA 108:18067-18072.

Peaker, M. 1980. The effect of raised intramammary pressure on mammary function in the goat in relation to the cessation of lactation. J. Physiol. 301:415-428.

Phyn, C. V. C., J. M. Dobson, S. R. Davis, K. Stelwagen, and K. Singh. 2007. Induced physical distension of rat mammary glands accelerates the onset of apoptosis and involution compared with milk accumulation alone. Proc. N.Z. Soc. Anim. Prod. 67:403-406.

Plath, A., R. Einspanier, F. Peters, F. Sinowatz, and D. Schams. 1997. Expression of transforming growth factors alpha and beta- 1 messenger RNA in the bovine mammary gland during different stages of development and lactation. J. Endocrinol. 155:501-511.

Poelmann, R. E., K. Van der Heiden, A. Gittenberger-de Groot, and B. P. Hierck. 2008. Deciphering the endothelial shear stress sensor. Circulation 117:1124-1126.

Poole, C. A., M. H. Flint, and B. W. Beaumont. 1985. Analysis of the morphology and function of primary cilia in connective tissues: A cellular cybernetic probe? Cell Motil. 5:175-193.

Praetorius, H. A., and K. R. Spring. 2001. Bending the MDCK cell primary cilium increases intracellular calcium. J. Membr. Biol. 184:71-79.

Quaglino, A., M. Salierno, J. Pellegrotti, N. Rubinstein, and E. Kordon. 2009. Mechanical strain induces involution-associated events in mammary epithelial cells. BMC Cell Biol. 10:55.
Quarrie, L. H., C. V. Addey, and C. J. Wilde. 1994. Local regulation of mammary apoptosis in the lactating goat. Biochem. Soc. Trans. $22: 178 \mathrm{~S}$.

Roth, K. E., C. L. Rieder, and S. S. Bowser. 1988. Flexible-substratum technique for viewing cells from the side: Some in vivo properties of primary $(9+0)$ cilia in cultured kidney epithelia. J. Cell Sci. 89:457-466.

Satir, P., and S. T. Christensen. 2007. Overview of structure and function of mammalian cilia. Annu. Rev. Physiol. 69:377-400.

Schwartz, E. A., M. L. Leonard, R. Bizios, and S. S. Bowser. 1997. Analysis and modeling of the primary cilium bending response to fluid shear. Am. J. Physiol. 272:F132-F138.

Schwartz, M. A. 2010. Integrins and extracellular matrix in mechanotransduction. Cold Spring Harb. Perspect. Biol. 2:a005066.

Shamay, A., F. Shapiro, G. Leitner, and N. Silanikove. 2003. Infusions of casein hydrolyzates into the mammary gland disrupt tight junction integrity and induce involution in cows. J. Dairy Sci $86: 1250-1258$

Singh, K., S. R. Davis, J. M. Dobson, A. J. Molenaar, T. T. Wheeler, C. G. Prosser, V. C. Farr, K. Oden, K. M. Swanson, C. V. Phyn, D. L. Hyndman, T. Wilson, H. V. Henderson, and K. Stelwagen. 2008. cDNA microarray analysis reveals that antioxidant and immune genes are upregulated during involution of the bovine mammary gland. J. Dairy Sci. 91:2236-2246.

Singh, K., J. Dobson, C. V. C. Phyn, S. R. Davis, V. C. Farr, A. J. Molenaar, and K. Stelwagen. 2005. Milk accumulation decreases expression of genes involved in cell-extracellular matrix communication and is associated with induction of apoptosis in the bovine mammary gland. Livest. Prod. Sci. 98:67-78.

Singla, V., and J. F. Reiter. 2006. The primary cilium as the cell's antenna: Signaling at a sensory organelle. Science 313:629-633.

Stelwagen, K. 2001. Effect of milking frequency on mammary functioning and shape of the lactation curve. J. Dairy Sci. 84:E204-E211.

Tong, X., R. Drapkin, R. Yalamanchili, G. Mosialos, and E. Kieff 1995. The Epstein-Barr virus nuclear protein 2 acidic domain forms a complex with a novel cellular coactivator that can interact with TFIIE. Mol. Cell. Biol. 15:4735-4744.

Veland, I. R., A. Awan, L. B. Pedersen, B. K. Yoder, and S. T. Christensen. 2009. Primary cilia and signaling pathways in mammalian development, health and disease. Nephron Physiol. 111:39-53.

Wann, A. K. T., N. Zuo, C. J. Haycraft, C. G. Jensen, C. A. Poole, S. R. McGlashan, and M. M. Knight. 2012. Primary cilia mediate mechanotransduction through control of ATP-induced Ca2+ signaling in compressed chondrocytes. FASEB J. 26:1663-1671.

Watson, C. J., and P. A. Kreuzaler. 2011. Remodeling mechanisms of the mammary gland during involution. Int. J. Dev. Biol. 55:757762.

Wells, R. G. 2013. Tissue mechanics and fibrosis. Biochim. Biophys. Acta 1832:884-890.

Wilde, C. J., C. V. Addey, L. M. Boddy, and M. Peaker. 1995. Autocrine regulation of milk secretion by a protein in milk. Biochem. J. 305:51-58.

Wilde, C. J., C. H. Knight, and D. J. Flint. 1999. Control of milk secretion and apoptosis during mammary involution. J. Mammary Gland Biol. Neoplasia 4:129-136.

Wilde, C. J., L. H. Quarrie, E. Tonner, D. J. Flint, and M. Peaker. 1997. Mammary apoptosis. Livest. Prod. Sci. 50:29-37.

Woods, A., T. Sherwin, R. Sasse, T. H. MacRae, A. J. Baines, and K. Gull. 1989. Definition of individual components within the cytoskeleton of Trypanosoma brucei by a library of monoclonal antibodies. J. Cell Sci. 93:491-500.

Zhang, W. J., B. H. Li, X. Z. Yang, P. D. Li, Q. Yuan, X. H. Liu, S. B. Xu, Y. Zhang, J. Yuan, G. S. Gerhard, K. K. Masker, C. Dong, W. A. Koltun, and M. J. Chorney. 2008. IL-4-induced Stat6 activities affect apoptosis and gene expression in breast cancer cells. Cytokine 42:39-47.

Zhou, J. 2009. Polycystins and primary cilia: Primers for cell cycle progression. Annu. Rev. Physiol. 71:83-113. 